Journal of Social Sciences 6 (2): 282-286, 2010

ISSN 1549-3652

(C) 2010 Science Publications

\title{
Impact of Firm's Characteristics on Determining the Financial Structure On the Insurance Sector Firms in Jordan
}

\author{
Ghazi F. Momani, Majed, A. Alsharayri and Mwafaq M. Dandan \\ Department of Banking and Financial Sciences, Arab Academy for Banking and Financial Sciences, \\ P.O. Box 13190, Amman 11942, Jordan
}

\begin{abstract}
Problem statement: The question of the funding structure took a great importance in developed countries, but it has been neglected in developing countries. Approach: This study came with the aim to examine the effect of the following factors: Volume, assets structure, return on assets and growth rate on the capital structure of the insurance sector companies listed in Amman stock market, which numbered 25 companies which have been in operation between the years 2000 and 2007. Results: The selection of the above mentioned variables have been chosen on a basis of simple and multiple regression where the study shows a significant difference between the company's special characteristic represented with volume, asset structure and return on assets, growth rate and capital structure. Conclusion/Recommendations: As long as the factors are positive which goes along with many other studies were undertaken by different authors, therefore the scholars advises using leverage to achieve the goals of the companies.
\end{abstract}

Key words: Financial structure, insurance sector, firm characteristics

\section{INTRODUCTION}

The issue of capital structure attracted the attention of a large number of researchers, as most of companies or business firms of any kind need a debt or the use of third party funds, in addition to private capital. But the important issue is the size of private capital and debt which should be increased in order to achieve the objectives of the institution to maximize the market value or to maximize the wealth. Therefore, the most recent studies have confirmed the existence of a relationship between the value of the company's capital structure, which means that the change in capital structure of the company affect the financial performance of the business and the value of the company where the access business to an optimal debt ratio would reduce the cost of capital and then raise the market value of companies, on the other hand, we find excessive use of debt leads to an increase in cost of capital.

From this point, the researchers found that it is important to study the financial decisions of the managers in determining the ratio of debt, the impact on the cost of funds and therefore the market value of the business and the indicators of the companies when they are choosing the company's financial structure. This study has been applied to the Jordanian insurance companies listed in Amman financial market, where decisions by managers to assess the financial insurance companies and to consider the impact of factors related to the company itself such as firm size, profitability, asset structure and growth rate on the decisions of chief financial officer on the selection of the capital structure of the company, therefore this study came to see how managers understand the impact of the financial characteristics of the company (firm size, profitability, asset structure, the company's life) which means that, managers take into consideration the financial characteristics of the company in the development of funding decisions on the structure of the company and the effectiveness of the banking sector in supporting companies and whether similar businesses in the selection of the funding structure or do they disagree with each other? If there is a difference, do they differ due to the properties of the company? For this purpose the researchers put the following hypotheses:

- There is a positive relationship with statistical significance between firm size and capital structure

- There is a positive relationship with statistical significance between the proportion of fixed assets and capital structure

- There is a positive relationship with statistical significance between the proportion of profitability ratios and capital structure

Corresponding Author: Ghazi F. Momani, Department of Banking and Financial Sciences,

Arab Academy for Banking and Financial Sciences, P.O. Box 13190, Amman 11942, Jordan 


\section{J. Social Sci., 6 (2): 282-286, 2010}

- There is a positive relationship with statistical significance between the growth rate of profits and capital structure

Importance of the study: Although the question of the funding structure took a great importance in developed countries, but it is neglected in developing countries for two reasons, firstly because there is no major economic role for companies in the developing countries and the second reason is that, the firms in many developing countries face several constraints in their choice of funding sources, such as lack of bond markets and the ineffectiveness of banks to finance investments, as the financial markets of the modern states (Tarek, 2007). The job of chief financial officer has become one of the most important jobs in the institutions and large corporations, as the financial management has become a specialty of its own, so it is important to provide knowledge of the types of specialists and the determinants of financing. However many studies were carried out in this field which came with different findings. Modigliani and Miller (1958) made a study in capital structure and cost which concluded that the value of the company is not affected by the financial structure of the company, through the assumption of efficient markets and the absence of corporate taxes or individuals and that interest is fixed irrespective of the ratio of debt used and there is no likelihood of bankruptcy. Voulgaris (2002) presented a research titled: "Capital structure and profitability, growth and structure of the assets in the industrial sector", This study examined the determinants of capital structure of the industrial sector, in the large Greek enterprises during the period between (1986-1998) where the study concluded that the structure of assets and the rate of growth and net profit, has no effect on the structure of capital for large projects and the ratio of debt to total assets has a strong correlation with the net profit and turnover of capital assets. Cassar and Holmes (2003) wrote a paper entitled: Capital structure and financing of small and medium-sized enterprises, This study examined the determinants of capital structure in small and medium enterprises in Australia, this study examined whether the characteristics of the company (size, rate of profit growth, profitability and asset structure) that can affect the capital structure, or not? The researcher used multiple-regression model, they suggested that the assets structure ratio, profitability and growth, play an important role in the financing of small and medium enterprises, there is no clear evidence of the impact of size and the risks to the capital structure.
Bancel and Mittoo (2004) Tested the capital structure and examining the role of legal institutions in explaining the difference in financial leverage and examined the views of managers in their choice of capital structure led by similar factors. Determinants of capital structure choice of the European companies, was compared to the views of the managers of the determinants of whether the differences in legal rules and regulations between the states role in the interpretation of the difference in financial leverage between nations. Where the study covered 16 European countries and found that the legal environment is important in a specific debt policy, playing a bigger role in policy, than ordinary shares. Bancel and Mittoo (2004) believed that the capital structure of companies is not only influenced by the company's factors, but also country-specific factors, the study identified factors that can affect the leverage of companies according to any country, where they found that the determinants of state can be directly affect the leverage, the existence of a developed bond market in the country facilitates, the exchange and sale of bonds, which leads to the use of corporate leverage is the highest in the country, while a stock market advanced in the country has a negative effects in the bond market developed to stimulate the use of debt, we find the structure of the company's assets is important for determining the impact of the ratio of debt companies that are in a country with a developed market bonds and has a low level of mortgage assets negotiable, they found that leverage is not increased, corporations characterized by a high level of mortgage assets negotiable. Tran and Khoig (2006) has studied the capital structure of small and medium-sized enterprises in Vietnam, during the period 1990-2001, depended not only on the characteristics of the company, but also on the management behavior which played an important role in external financing and the relationship between the firms and the banks which has an important impact in determining the leverage ratio, which is therefore a clear in public companies more than in private companies and the size of the company and business risks has appositive relationship with debt ratio and found that profitability and asset structure do not have a clear impact on the debt ratio in Vietnamese companies.

\section{MATERIALS AND METHODS}

This study attempts to analyze the impact of firm's characteristics on determining the financial structure of the insurance sector firms in Jordan covering all Jordanian insurance companies listed on the Amman Stock Exchange during the period between 2000-2007, 
using for this purpose the statistical analysis package (SPSS) for analysis and data processing and will use the simple and multiple regression to test hypotheses of the study and test the KS-test to make sure the data subject of the normal distribution prior to regression testing, in addition to that test can be used t-test for the purposes of hypothesis testing. The Correlation Matrix will be used to find out the correlation between the independent variables with each other and between the independent variable and the dependent variable:

- Model of the study: Researchers use multiple regression model to test the impact of independent variables at the dependent variable and so on as follows:

$$
D=\alpha_{1}+\beta_{1 \times 1}+\beta_{2 \times 2}+\beta_{3 \times 3}+\beta_{4 \times 4}
$$

Where:

$$
\begin{array}{lrl}
\mathrm{D} & =\text { To the variable proportions of a } \\
& \text { total debt to total assets } \\
= & \text { To interest } \\
\alpha_{1} & \text { Model coefficients } \\
\beta_{0}, \beta_{1}, \beta_{2}, \beta_{3}, \beta_{4} & \text { To the size of the company } \\
\mathrm{x}_{1} & \text { measured the volume of assets } \\
& \text { logarithm } \\
= & \text { Profit equals revenue before } \\
& \text { interest and taxes to total assets } \\
\mathrm{x}_{2} & \text { Tangibility equals the book value } \\
& \text { of fixed assets to total assets } \\
\mathrm{x}_{3} & \text { Growth equals the percentage of } \\
& \text { book value to market value }
\end{array}
$$

Analyze the results and hypothesis simple linear regression will be used to analysis to measure the relationship between each independent variable with the dependent variable and multiple regression for the measured relationship between the dependent variable and independent variables.

Sources of data: The study will be based on the following sources:

- Primary sources: The data will be collected through bulletins and statistics issued by the Amman stock exchange, lists and financial reports for insurance companies listed on the Amman stock exchange and statistics released by the central bank of Jordan

- Secondary sources: Published books, periodicals and scientific journals
Objectives of the study: This study aims to:

- Study the variables in the joint-stock companies such as size of company, profitability, structure of assets and the rate of earnings growth and its impact on the structure of financing

- Evaluation of the degree suitability of the financial structure of the company with its financial ratios

- Testing the impact of capital market variables, the tax rate and the interest rate on structuring capital

\section{RESULTES}

\section{Results of testing the study hypotheses:}

- There is a statistically significant relation between firm size and capital structure. The results contained in the statistical Table 1 show a positive relationship between firm size and financial structure in insurance sector companies listed on the ASE, the total coefficient of determination (0.85), this means, the ability of variable size of the company to explain the change in financial structure is $85 \%$, which a relatively high proportion. The value of $\mathrm{T}$ calculated has statistical significance at the 5\% level of morale and thus the null hypothesis is rejected we will accept the alternative hypothesis, which states the existence of the impact of the size of the company's financial structure

- There is a statistically significant relation between the structure of the company's assets and capital structure of the company Statistical results indicate in the Table 2 a positive relationship between the structure of the company's assets and capital structure of insurance sector listed on the ASE, the total coefficient of determination (0.919), This means the ability of changing the structure of the assets of the company to explain the change in financial structure. The value of $\mathrm{T}$ calculated has statistical significance at the 5\% level of morale and thus the null hypothesis is rejected, which states that there is no trace of the structure of the assets of the company's capital structure and accept the alternative hypothesis, which states the existence of the impact of the structure of the company's assets on the capital structure

Table 1: Summaries of the statistical results of the simple linear regression analysis of the first hypothesis

\begin{tabular}{lllllll}
\hline Variable & Constant & Sig. & T & $\mathrm{R}^{2}$ & Sig. & F \\
\hline 0.013074 & 0.343667 & 0.00 & 9.098186 & 0.877124 & 0.000 & 85.11021 \\
\hline
\end{tabular}




\section{J. Social Sci., 6 (2): 282-286, 2010}

Table 2: A summary of the statistical results of the simple linear regression analysis of the second hypothesis

\begin{tabular}{lllllll}
\hline Variable & Constant & Sig. & T & $R^{2}$ & Sig. & F \\
\hline 0.013074 & 0.343667 & 0.00 & 9.098186 & 0.877124 & 0.00 & 85.11021 \\
\hline
\end{tabular}

Table 3: A summary of the statistical results of the simple linear regression analysis of the third hypothesis

\begin{tabular}{lllllll}
\hline Variable & Constant & Sig. & T & $\mathrm{R}^{2}$ & Sig. & $\mathrm{F}$ \\
\hline 0.0051 & 0.554798 & 0.00 & 50.39572 & 0.907485 & 0.00 & 116.9546 \\
\hline
\end{tabular}

Table 4: A summary of the statistical results of the simple linear regression analysis of the fourth hypothesis

\begin{tabular}{lllllll}
\hline Variable & Constant & Sig. & T & $R^{2}$ & Sig. & F \\
\hline-2677 & 0.554798 & 0.0000 & 56.00825 & 0.919350 & 000 & 135.914 \\
\hline
\end{tabular}

Table 5: A summary of the statistical results of the simple linear regression analysis of the fifth hypothesis

\begin{tabular}{lllllll}
\hline Variables & Variables & $\mathrm{T}$ & Sig. & $\mathrm{R}^{2}$ & $\mathrm{~F}$ & Sig. \\
\hline Constant & 0.2630 & 5.940 & 0.0003 & $0.8769+$ & 67.6795 & \\
Size of company & 0.0169 & 5.340 & 0.0000 & & \\
Structure of assets & 0.1721 & 2.020 & 0.0450 & & \\
Return on assets & -0.5000 & -3.580 & 0.0005 & & \\
Growth rate & 0.8600 & 2.353 & 0.0199 & & \\
\hline
\end{tabular}

- There is a statistically significant relation between the return on assets and capital structure statistical results indicate in the Table 3 the existence of a positive correlation between return on assets and capital structure of companies in insurance sector listed on the ASE, the total coefficient of determination (0.90), this means the ability of variable size of the company to explain the change in capital structure is $90 \%$, which is relatively high. The value of $\mathrm{T}$ calculated has statistical significance at the 5\% level of morale and thus the null hypothesis is rejected, which states that there is no trace of the return on assets on the financial structure and we accept the alternative hypothesis which states that a trace of return on assets on the capital structure

- There is a statistically significant relation between the rate of growth and capital structure. Statistical results indicate in the Table 4 the existence of a positive correlation between return on assets and financial structure of the insurance sector companies listed on the ASE, the total coefficient of determination (0.92), i.e., the ability of variable size of the company to explain the change in financial structure is $92 \%$ which is relatively high. The value of (t) calculated has statistical significance at the 5\% level of morale and thus the null of the return on assets on the capital structure and to accept the alternative hypothesis which states that a trace of return on assets on the financial structure

- There is a statistically significant relation between the independent variables together and the capital structure. Through Table 5 which shows the results of hypothesis testing multi regression results showed that the size of the company was positive and statistically significant at the level of morale (0.05), indicating the positive impact of the volume of assets on the capital structure regression results showed that the structure of assets was positive and statistically significant at the level of morale (0.05), indicating the positive impact of the structure of assets on the capital structure and regression results showed that the return on assets was negative and statistically significant at the level of morale (0.05), indicating the negative impact of the return on assets on the capital structure and regression results showed that the rate of growth was positive. No matter how statistically significant at the level of (0.05), indicating the positive impact of growth on the financial structure, the value of the rate coefficient of determination (Adjusted R-squared) (0.87) which indicates that the independent variables explain what the company's percentage $(87 \%)$ of the contrast happening in the financial structure and the calculated value of $\mathrm{P}$ 67.67, where it was statistically significant at the level of morale $(0.05)$

\section{DISCUSSION}

- The null hypothesis were rejected, which provides for the absence of a statistically significant relation between firm size and capital structure and accept the alternative hypothesis, which provides for a statistically significant relation between firm size and capital structure

- The null hypothesis were rejected, which states that there is no trace of the structure of the assets of the company's financial structure and accepted the 
alternative hypothesis, which states the existence of the impact of the structure of the assets of the company's financial structure

- The null hypothesis was rejected, which states that there is no trace of the return on assets on the financial structure and accept the alternative hypothesis which states that a trace of return on assets on the financial structure

- The null hypothesis was rejected, which states that there is no trace of the return on assets on the financial structure and to accept the alternative hypothesis which states that a trace of return on assets on the financial structure

- It has been confirmed on the existence of a statistically significant relation between the independent variables together and capital structure However the results of this study consistent with a number of previous studies such as the study of Cassar and Holmes (2003); Bancel and Mittoo (2004) and study of Tran and Khoig (2006). There was one study come out with opposite result such as study of Voulgaris (2002).

\section{CONCLUSION}

- More care to be given to financial indicators of the company (the size of the company, the structure of assets, profitability, growth rate) and monitoring of these indicators over a period of time so that these indicators increase from time to time and can be compared with the average financial indicators for all companies in the same sector, in the case when the size of the company's assets, the proportion of fixed assets and the rate of growth of the company are higher than average rates of the average sector as a whole, it is logical that the ratio of debt financial structure to this company is higher than the sector average

- Researchers recommend that insurance sector companies place in mind and consider the financial indicators relating to the capital market, for such variables are important to reduce the cost of capital as the interest rates on loans and the tax rate plays a significant role in reducing the cost of capital, which in turn leads to an increase in the market value of companies, as well as consolidating good relations with commercial banks and investment in creating opportunities for negotiation with the banks in order to obtain low and competitive interest rates to reduce the cost of financing for the company
- Researchers recommend that companies with high growth rates of profitability and seek to expand their investments and use profits to finance investment and by relying on internal sources of funding and covering needs by withhold part of the generated profits, since it is a source of cheap funding compared to funding sources other

\section{REFERENCES}

Bancel, F. and U. Mittoo, 2004. Cross-country determinants of capital structure choice, Survey of European firms. Fin. Manage. J., 33: 103-132.

Cassar, G. and S. Holmes, 2003. Capital structure and financing of SMES: Australian evidence. Account. Fin. J., 43: 123-147. DOI: 10.1111/1467-629X.t011-00085

Modigliani, F. and Miller, 1958. The cost of capital, corporate finance and theory investment. Am. Econ. $\quad$ Rev., $\quad 48:$ 261-297. http://www.jstor.org/pss/1809766

Tran, N.D. and R.N. Khoig, 2006. Capital Structure in Small and Medium-sized Enterprises: The case of Vietnam. ASEAN Econ. Bull. 23: 192-211. DOI: 10.1353/ase.2007.0006

Tarek, I.E., 2007. Determinants of corporate leverage. Int. J. Comm. Manage., 17: 25-43. DOI: 10.1108/10569210710774730

Voulgaris, D., 2002. Capital structure, asset utilization, profitability and growth in the Greek. J. Applied Econ., 34 : 1379-1388. $\quad$ DOI: $10.1080 / 00036840110096822$ 